\title{
Salvage esophagectomy for recurrent tumors after definitive chemotherapy and radiotherapy
}

Stephen G. Swisher, MDa

Paula Wynn ${ }^{\mathrm{a}}$

Joe B. Putnam, MDa

Melinda B. Mosheima

Arlene M. Correa ${ }^{\mathrm{a}}$

Ritsuko R. Komaki, MD

Jaffer A. Ajani, MDC

W. Roy Smythe, MDa

Ara A. Vaporciyan, MDa

Jack A. Roth, MDa

Garrett L. Walsh, MDa

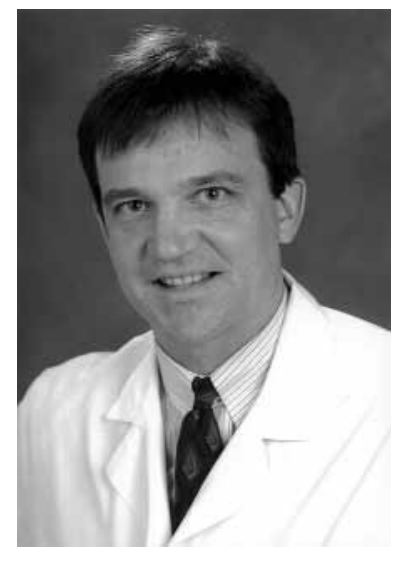

Dr Swisher
From the Department of Thoracic and Cardiovascular Surgery, ${ }^{a}$ Department of Radiation Oncology, ${ }^{\mathrm{b}}$ and Department of Gastrointestinal Oncology, ${ }^{c}$ The University of Texas M.D. Anderson Cancer Center, Houston, Tex.

Read at the Eighty-first Annual Meeting of The American Association for Thoracic Surgery, San Diego, Calif, May 6-9, 2001

Received for publication May 14, 2001; revisions requested June 15, 2001; revisions received July 18, 2001; accepted for publication July 18, 2001

Address for reprints: Stephen G. Swisher, MD, The University of Texas M.D Anderson Cancer Center, Department of Thoracic and Cardiovascular Surgery, 1515 Holcombe Blvd, Box 445, Houston, TX 77030 (E-mail: sswisher@mdanderson.org).

J Thorac Cardiovasc Surg 2002;123:175-83

Copyright (c) 2002 by The American Association for Thoracic Surgery.

$0022-5223 / 2002 \$ 35.00+0 \quad \mathbf{1 2 / 6 / 1 1 9 0 7 0}$ doi: $10.1067 / \mathrm{mtc} .2002 .119070$
Objectives: Some patients and oncologists choose to treat localized esophageal cancer with definitive chemotherapy and radiation therapy rather than surgery. A subset of these patients have local relapse without distant metastases and therefore have no other curative intent treatment option but salvage esophagectomy.

Methods: We reviewed our experience with salvage esophagectomy from 1987 to 2000 at M.D. Anderson Cancer Center ( $\mathrm{n}=13$, salvage after chemotherapy and radiotherapy group) and compared the data with those of patients receiving esophagectomy in a planned fashion 4 to 6 weeks after preoperative chemotherapy and radiation therapy $(\mathrm{n}=99$, preoperative chemotherapy and radiotherapy group).

Results: Increases in morbidity were seen after resection in the salvage after chemotherapy and radiotherapy group relative to the preoperative chemotherapy and radiotherapy group: mechanical ventilation (9.0 days vs 3.3 days, $P=.08$ ), intensive care unit stay (11.2 days vs 5.1 days, $P=.07$ ), hospital stay (29.4 days vs 18.4 days, $P=.03$ ), and anastomotic leak rates (5/13 [39\%] vs 7/99 [7\%], $P=.005)$. Operative mortality (within 30 days) also tended to be increased statistically nonsignificantly $(2 / 13[15 \%]$ vs $6 / 99$ [6\%], $P=.2)$. Salvage esophagectomy resulted in long-term survival (25\% 5-year survival) in a subset of patients. Improved survival after salvage esophagectomy was associated with early pathologic stage (T1 N0, T2 N0), prolonged time to relapse, and R0 surgical resection.

Conclusion: Patients who undergo salvage esophagectomy for relapse of tumor after definitive chemoradiation therapy have increased morbidity, mortality, and hospital use relative to patients undergoing planned esophagectomy after preoperative chemoradiation. Nevertheless, long-term survival can be achieved in this group, and such treatment should be considered for carefully selected patients at an experienced center.

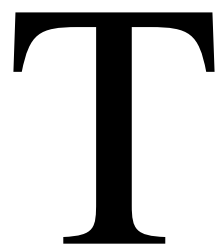

he optimal therapy for locoregionally advanced esophageal cancer has not yet been determined. Some groups advocate surgical resection for all patients, either alone or in combination with preoperative chemotherapy or chemoradiation therapy.$^{1-4}$ Other oncologists advocate a primarily nonsurgical approach with definitive chemoradiation therapy alone..$^{5-9}$ Although long-term survival can be achieved 
TABLE 1. Demographic factors

\begin{tabular}{lccc}
\hline & $\begin{array}{c}\text { Salvage after } \\
\text { chemotherapy and } \\
\text { radiotherapy group } \\
\text { (n= 13) }\end{array}$ & $\begin{array}{c}\text { Preoperative } \\
\text { chemotherapy and } \\
\text { radiotherapy group } \\
\text { (n = 99) }\end{array}$ & P value \\
\hline Sex (No.) & & & \\
Male & $9(69 \%)$ & $83(84 \%)$ & .24 \\
Female & $4(31 \%)$ & $16(16 \%)$ & \\
Age (y) & & & \\
Median & 65 & $61(39-84)$ & \\
Range & $45-83$ & $74(75 \%)$ & .05 \\
Histologic type (No.) & & $22(22 \%)$ & \\
Adenocarcinoma & $6(46 \%)$ & $3(3 \%)$ & \\
Squamous cell & $7(54 \%)$ & & \\
Other & 0 & $0(0 \%)$ & .00002 \\
Location (No.) & & $1(1 \%)$ & \\
Cervical & $1(8 \%)$ & $19(19 \%)$ & \\
Upper & $3(23 \%)$ & $79(80 \%)$ & \\
Middle & $3(23 \%)$ & & \\
Lower & $6(46 \%)$ & $21(21 \%)$ & .55 \\
Pathologic stage (No.) & & $16(16 \%)$ & \\
Stage 0 & $0(0 \%)$ & $21(21 \%)$ & \\
Stage I & $2(15 \%)$ & $15(15 \%)$ & \\
Stage IA & $5(38 \%)$ & $7(16 \%)$ & \\
Stage IB & $2(15 \%)$ & $3(3 \%)$ & \\
Stage III & $3(23 \%)$ & & \\
Stage IVA & $1(8 \%)$ & $0(0 \%)$ & \\
Stage IVB & $05 \%)$ & \\
\hline
\end{tabular}

through this nonoperative strategy, locoregional failure is still a major problem, with $40 \%$ to $60 \%$ of patients having recurrent locoregional disease. ${ }^{5,6} \mathrm{We}$ have therefore been faced with a subset of patients referred to our institution who have had locoregional failure occur after definitive chemoradiation therapy at an outside institution. Unfortunately, many of these patients are not eligible for salvage esophagectomy because of metastases found during restaging or physiologic deterioration that makes surgical risk prohibitive. Additionally, many of these patients are at increased risk for esophagectomy because they have been treated with higher doses of radiation and have completed radiation treatment many months before. Despite these increased risks, we have undertaken salvage esophagectomy for a subset of these patients who are physiologically fit for operation and have no evidence of distant metastases.

In an attempt to determine the outcome of salvage esophagectomy, we conducted a retrospective review of all patients undergoing esophageal resection $(n=780)$ between 1987 and 2000 at our institution and selected all patients undergoing salvage esophagectomy $(\mathrm{n}=13)$ for primary relapsed tumors after failed definitive chemoradiation therapy. This group was compared with a control group of patients $(\mathrm{n}=99)$ who during the same period underwent esophageal resection as a planned procedure 4 to 6 weeks after preoperative chemoradiation therapy.

\section{Patients and Methods}

We selected the records of all patients who underwent esophageal resection $(n=780)$ between August 1987 and February 2000 at M.D. Anderson Cancer Center and reviewed the cases of patients $(n=13)$ who underwent salvage esophageal resection for recurrent esophageal tumors after definitive chemotherapy and radiation therapy. Most of these patients were treated initially with chemotherapy and radiation therapy at an outside institution and came to M.D. Anderson Cancer Center for evaluation after relapse of the primary tumor. For comparison, we reviewed a group of patients $(n=99)$ treated with planned esophageal resection immediately (4 to 6 weeks) after preoperative chemotherapy and radiation therapy at M.D. Anderson Cancer Center during the same period. Hospital records were reviewed for age, sex, weight, height, American Society of Anesthesiology risk classification, preoperative medical history, pulmonary function test performance, tumor location and histologic class, and results of preoperative laboratory and radiographic studies. All medical charts were reviewed for details regarding definitive or adjuvant chemotherapy and radiation therapy, including radiation dose and chemotherapy drug type. Outside hospital records from patients initially treated with definitive chemotherapy and radiation therapy were reviewed as appropriate for details regarding treatment. Data collected included the dates of treatment, time to tumor relapse, operative time, estimated blood loss, transfusion requirements, and technical surgical details. Perioperative pathology reports were reviewed to determine pathologic stage and surgical resection margins.

Short-term outcome was evaluated by reviewing duration of ventilator dependence, days spent in the intensive care unit, days spent in the hospital, anastomotic leak rate, and death before discharge (30-day mortality). Long-term outcomes, encompassing overall survival and recurrence rates (local and distant), were obtained from hospital records and the M.D. Anderson Cancer Center tumor registry. Overall survival was calculated from the day of operation until the last known date of follow-up.

Statistical analysis was performed in association with our departmental biostatisticians (M.B.M. and A.M.C.). Statistical analysis included the Student $t$ test, the Pearson $\chi^{2}$ test, and the Fisher exact test as appropriate. The survival functions were estimated with the Kaplan-Meier method estimator, and log-rank tests were used to compare the survival distributions. Univariable and multivariable analyses for survival in the salvage after chemotherapy and radiotherapy group was performed on the 11 patients who survived the perioperative period. Multivariable analysis was performed by Cox regression and included all the variables that were statistically significant or clinically relevant in the univariable analyses. Software used included Microsoft Excel (Microsoft Corporation, Redmond, Wash), Graph Pad Prism (GraphPad Software, Inc, San Diego, Calif), and SPSS (SPSS Inc, Chicago, IIl) statistical software.

\section{Results}

\section{Characteristics of Patients}

Thirteen patients underwent esophageal resection as a salvage procedure for recurrent esophageal tumors after failed 
definitive chemotherapy and radiation therapy (salvage after chemotherapy and radiotherapy group) between August 1987 and February 2000 at M.D. Anderson Cancer Center. Most of these 13 patients were initially treated at an outside hospital with definitive chemotherapy and radiation therapy and were seen at M.D. Anderson Cancer Center after relapse of the primary tumor. Only patients who had recurrence in the same location as the original tumor were included. A control group of 99 patients who underwent esophageal resection as a planned procedure immediately (4-6 weeks) after preoperative chemotherapy and radiation therapy were used as a comparison group.

The two groups (salvage after chemotherapy and radiotherapy group and preoperative chemotherapy and radiotherapy group) were similar in sex distribution and pathologic stage (Table 1). Their preoperative American Society of Anesthesiology scores, weight loss, pulmonary function tests and medical comorbidities were also similar (data not shown). Patients in the salvage after chemotherapy and radiotherapy group tended to have a higher proportion of squamous cell carcinoma and cervical or upper location (4/13 [31\%] vs $1 / 99$ [1\%]) than those in the preoperative chemotherapy and radiotherapy group.

The average time to relapse for the salvage after chemotherapy and radiotherapy group was 18.1 months (range 4.1-55.9 months) after completion of definitive chemoradiation therapy. Patients who had relapse after definitive chemoradiation therapy were screened for metastatic disease by bone scan, computed tomography (CT) of the brain, and CT of the chest and abdomen. Only patients who did not show signs of metastatic disease and were deemed physiologically fit were evaluated for resection. The preoperative chemotherapy and radiotherapy group underwent resection immediately (4-6 weeks) after preoperative chemoradiation therapy only if repeated CT of the chest and abdomen showed no evidence of metastatic disease. The average dose of radiation delivered to the esophagus in the salvage after chemotherapy and radiotherapy group was $56.7 \mathrm{~Gy}$ (range 30.0-90.0 Gy), as opposed to 41.4 Gy (range 30.0-60.0 Gy) in the preoperative chemotherapy and radiotherapy group; this difference was statistically significant $(P=.002)$. Both groups received regimens composed predominantly of 5-fluorouracil and cisplatin concomitantly with radiation therapy. A minority of patients $(n=38)$ in the preoperative chemotherapy and radiotherapy group also received paclitaxel, cisplatin, and 5-fluorouracil before chemoradiation therapy.

\section{Perioperative Factors}

The salvage after chemotherapy and radiotherapy group (Table 2) tended to have an increased number of cervical anastomoses, reflecting a higher proportion of transhiatal (cervical anastomosis) and three-field esophagectomies (transthoracic
TABLE 2. Perioperative factors

\begin{tabular}{|c|c|c|c|}
\hline & $\begin{array}{l}\text { Salvage after } \\
\text { hemotherapy and } \\
\text { adiotherapy group } \\
\qquad(\mathrm{n}=13)\end{array}$ & $\begin{array}{c}\text { Preoperative } \\
\text { chemotherapy and } \\
\text { radiotherapy group } \\
\text { (n= 99) }\end{array}$ & Pvalue \\
\hline \multicolumn{4}{|l|}{ Location of anastomosis (No.) } \\
\hline \multicolumn{4}{|l|}{ Cervical } \\
\hline Transhiatal & $2(15 \%)$ & $16(16 \%)$ & $.13^{*}$ \\
\hline Transthoracic three-field & Id $6(46 \%)$ & $21(21 \%)$ & \\
\hline Total & $8(61 \%)$ & $47(37 \%)$ & \\
\hline \multicolumn{4}{|l|}{ Thoracic } \\
\hline Transthoracic Ivor-Lewis & jis $5(38 \%)$ & $58(59 \%)$ & \\
\hline Transabdominal & 0 & $4(4 \%)$ & \\
\hline Total & $5(38 \%)$ & $62(63 \%)$ & \\
\hline \multicolumn{4}{|l|}{ Operative factors } \\
\hline Operative time (min) & $542 \pm 172$ & $429 \pm 141$ & .006 \\
\hline Blood loss (mL) & $1212 \pm 832$ & $843 \pm 527$ & .07 \\
\hline $\begin{array}{l}\text { Packed red blood } \\
\text { cells (U) }\end{array}$ & $1.9 \pm 2.5$ & $0.9 \pm 1.4$ & .09 \\
\hline \multicolumn{4}{|l|}{ Hospital factors } \\
\hline $\begin{array}{l}\text { Mechanical } \\
\text { ventilation (d) }\end{array}$ & $9.0 \pm 13.3$ & $3.3 \pm 8.1$ & .08 \\
\hline $\begin{array}{l}\text { Intensive care unit } \\
\text { stay (d) }\end{array}$ & $11.2 \pm 13.3$ & $5.1 \pm 9.4$ & .06 \\
\hline Hospital stay (d) & $29.4 \pm 22.4$ & $18.4 \pm 18.3$ & .03 \\
\hline Anastomotic leak (No.) & $5(38 \%)$ & $7(7 \%)$ & .005 \\
\hline Operational mortality $(30 \mathrm{~d})$ & d) $2(15 \%)$ & $6(6 \%)$ & .2 \\
\hline
\end{tabular}

Noncategorical data expressed as mean \pm SD.

${ }^{*}$ Cervical versus thoracic anastomosis.

with cervical anastomosis) rather than Ivor Lewis esophagectomies (transthoracic with chest anastomosis). Anastomotic techniques in the groups were similar, with neck anastomoses being performed with a single layer interrupted suture technique and chest anastomoses being performed with a 2-layer interrupted suture or stapled technique. The operative time, blood loss, and units of transfused packed red blood cells were increased in the salvage esophagectomy group, which may reflect increased complexity or difficulty of resecting the relapsed tumors (Table 2).

The immediate postoperative courses of the groups also differed. Patients undergoing salvage esophagectomy had increases in the durations of ventilator dependence, intensive care unit stays, and overall hospital stays (Table 2). Additionally, the anastomotic leak rate was significantly increased in the salvage esophagectomy group. Perioperative (30-day) mortality also showed a tendency to be increased after salvage esophagectomy.

Further detailed review of the 13 patients who underwent salvage esophagectomy revealed that adverse events were noted in $77 \%(10 / 13)$. Sixty-two percent (8/13) of the patients had some pulmonary complication, with the most 


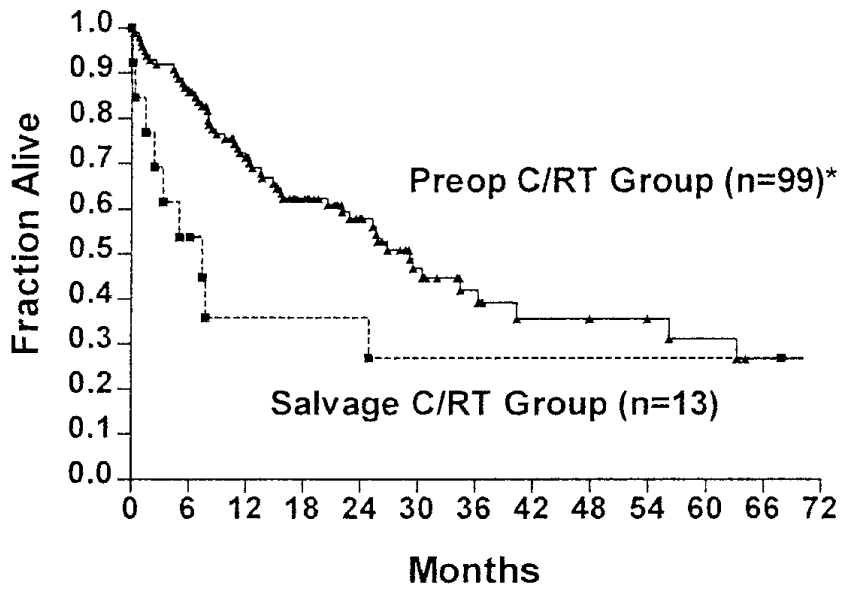

Figure 1. Overall survival of patients undergoing esophagectomy after definitive chemoradiation therapy (salvage after chemotherapy and radiotherapy, $n=13$ ) or planned preoperative chemoradiation therapy (preoperative chemotherapy and radiotherapy, $\mathrm{n}=$ 99). C/RT, Chemotherapy and radiotherapy.

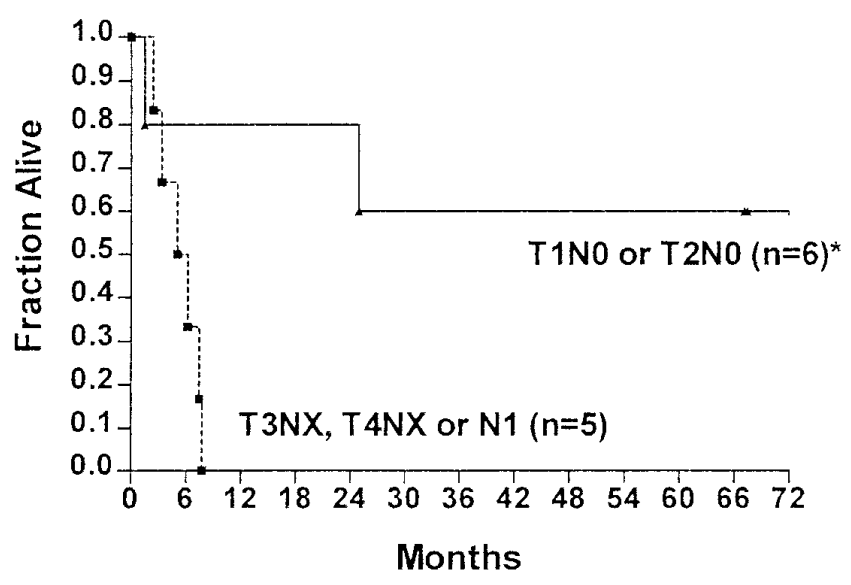

Figure 2. Long-term survival of patients after salvage esophagectomy $(n=11)$ according to pathologic stage (excluding perioperative deaths, $n=2$ ).

common being pneumonia ( 5 patients) or ventilatory support exceeding 48 hours (4 patients). Two patients (15\%) required tracheostomies for respiratory insufficiency and long-term pulmonary care. Infections were the second most common complication, occurring in $31 \%$ (4/13), and were primarily wound related. Other complications included renal failure $(n=1)$, gastric outlet obstruction $(n=1)$, and ischemic conduit $(\mathrm{n}=1)$. No difference was noted in the leak rates with thoracic or cervical anastomoses in the salvage after chemotherapy and radiotherapy group (thoracic anastomosis $2 / 5$ [40\%] vs cervical anastomosis $3 / 8$ [38\%]). Neither patient who died during the perioperative period

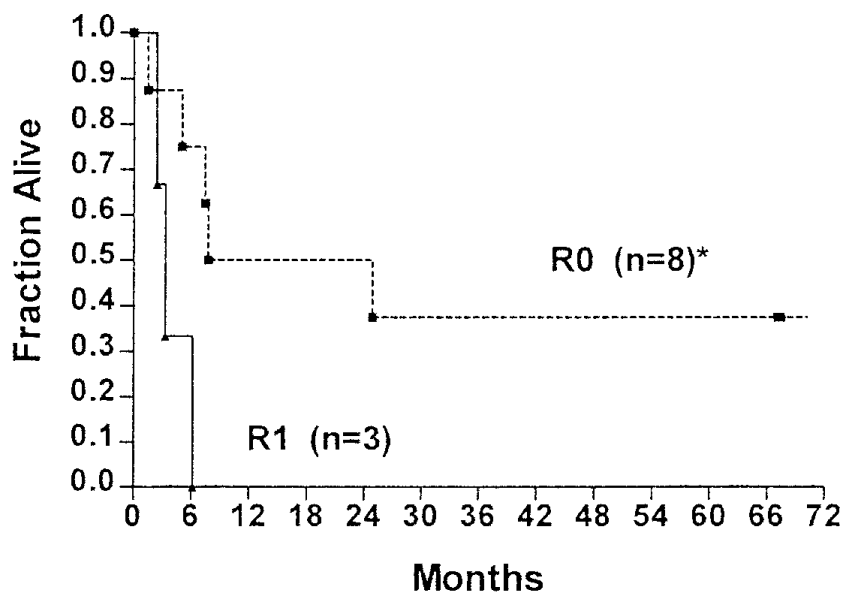

Figure 3. Long-term survival of patients after salvage esophagectomy ( $\mathbf{n}=11$ ) according to $\mathrm{RO}$ resection status (excluding perioperative deaths, $n=2$ ).

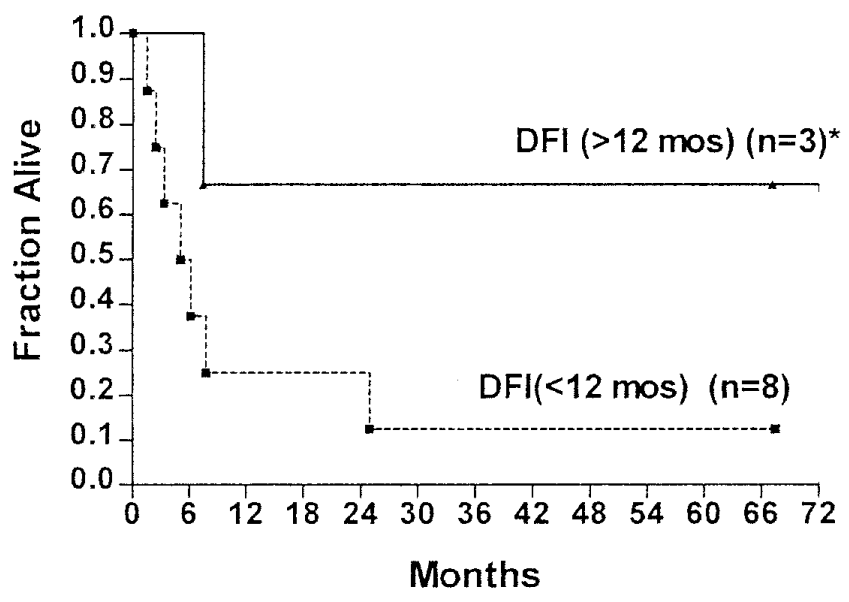

Figure 4. Long-term survival of patients after salvage esophagectomy ( $n=11$ ) according to disease free-interval (DFI) longer than 12 months (excluding perioperative deaths, $n=2$ ).

had a thoracic anastomosis, although 1 patient with a cervical anastomosis died because of a leak from the lesser curvature into the thoracic cavity. Both patients who died during the perioperative period $(n=2)$ had relapse occur longer than 50 months after definitive chemoradiation therapy, whereas all surviving patients $(n=11)$ had relapse occur 24 months or less after chemoradiation therapy $(P=$ $.01)$. One perioperative death was due to adult respiratory distress syndrome and multiorgan failure, whereas the other was due to a leak on the lesser curvature with subsequent sepsis. No relationship was found between salvage esophagectomy morbidity, leak rate, or length of hospital- 
ization and dose of radiation, time to relapse, location of anastomosis, type of operative procedure, or other preoperative risk factors.

\section{Long-Term Outcome}

The pathologic staging of disease in the 13 patients undergoing salvage esophagectomy was not significantly different from that of those undergoing esophagectomy after preoperative chemotherapy and radiotherapy (Table 1). Despite differences in operative mortality and morbidity, long-term survivals were similar (Figure 1). Salvage esophagectomy was associated with long-term survival (5-year 25\%) in a subset of patients, with 4 patients living longer than 2 years after the operation and 2 patients still alive without evidence of disease 5.7 years and 12.2 years after the salvage operation. In an attempt to determine factors associated with longterm survival after salvage esophagectomy, the 11 patients who survived the perioperative period were evaluated for various factors. Univariate analysis revealed that early ( $\mathrm{T} 1$ N0, T2 N0) stage, R0 resection, and prolonged disease-free interval (or time to relapse) were associated with increased survival (Figures 2, 3, and 4). Multivariable analysis revealed that the most significant factor appeared to be early pathologic stage (hazard ratio $=6.045, P=.127$ ), although this was not statistically significant because of the low number of patients in the analysis and the overlap between early stage and $\mathrm{R} 0$ resection (Table 3 ).

With a median follow-up of 27 months, 3 of 11 of the patients in the salvage esophagectomy group who survived the operation demonstrated locoregional recurrences (27\%). Two other patients (18\%) had distant recurrences (bone and liver). Four patients $(36 \%)$ showed no evidence of tumor recurrence after salvage esophagectomy and survived for a prolonged period with excellent swallowing function, whereas 2 patients (18\%) showed no evidence of recurrence but died within 6 months after the operation, possibly of tumor relapse. Recurrence data were not applicable in 2 cases because the patients died before discharge as a result of operative complications rather than tumor recurrence.

\section{Discussion}

The optimal treatment strategy for locoregionally advanced esophageal cancer has not yet been determined. Esophagectomy either alone or in combination with chemotherapy and radiation therapy is associated with longterm survivals of only $15 \%$ to $35 \% .^{1-4}$ Additionally, many of these patients have significant weight loss and associated comorbidities and are at high risk for perioperative morbidity and mortality after an extensive surgical procedure such as esophagectomy. ${ }^{10}$ Because of these poor outcomes with surgery, alternative treatment strategies have been proposed by some oncologists to treat locoregionally advanced esophageal cancer with definitive chemoradiation therapy
TABLE 3. Multivariable analysis of salvage esophagectomy long-term survival

\begin{tabular}{lccc}
\hline Factor & Hazard ratio & $\begin{array}{c}\text { 95\% Confidence } \\
\text { interval }\end{array}$ & $\boldsymbol{P}$ value \\
\hline Relapse, $<12$ mo vs $\geq 12$ mo & 1.439 & $0.250-8.270$ & .684 \\
Resection, R1 vs R0 & 2.611 & $0.375-18.204$ & .333 \\
Stage, advanced stage & 6.045 & $0.599-60.993$ & .127 \\
$\quad$ (T3, T4, or N1) vs & & & \\
$\quad$ early stage & & & \\
$\quad$ (T1 N0, T2 N0) & & & \\
\hline
\end{tabular}

and no surgery. ${ }^{5-7,9}$ These strategies, especially for squamous cell cancer, can result in long-term survivals of $10 \%$ to $30 \%$ when 5-fluorouracil and cisplatin or mitomycin are combined with radiation therapy. $6,11,12$ Unfortunately, locoregional control is often quite poor with definitive chemoradiation therapy, and $40 \%$ to $60 \%$ of the patients have persistent or relapsed tumor at the primary site within 1 year. ${ }^{5,6}$ Because of this we have been faced with a number of patients referred to us from outside institutions who have been treated with definitive chemoradiation therapy and have locoregional relapse, and there are few other curative intent treatment options except surgery. Because of the potentially increased risks associated with the higher doses of radiation received and the prolonged time from the completion of radiation therapy, many surgeons have been reluctant to operate on this group. This study therefore evaluated our experience with salvage esophagectomy after definitive chemoradiation therapy and compared it with a control group of patients who underwent esophagectomy as a planned procedure 4 to 6 weeks after completion of chemoradiation therapy. Although the control group was not a perfect comparison because of demographic differences in tumor and patient factors (Table 1), it still provided a baseline to assess the feasibility of salvage esophagectomy after failed definitive chemoradiation.

The number of patients $(n=13)$ undergoing salvage esophagectomy during this period was relatively small in light of the large number of esophagectomies performed at our institution $(\mathrm{n}=780)$. This may have been due in part to the fact that many patients who had locoregional failure after definitive chemoradiation therapy also had distant failure precluding surgical resection for cure. Additionally, our departmental protocols have involved operative approaches with or without chemotherapy or radiation therapy, and currently our approach for resectable esophageal cancer involves surgical resection in combination with preoperative chemoradiation therapy. We have reserved definitive chemoradiation therapy without surgery for patients who are not physiologically fit to undergo an operation or have 
upper or cervical esophageal tumors, where a laryngectomy might be required. ${ }^{13,14}$ This treatment algorithm may also explain the preponderance of cervical and upper esophageal tumors and squamous cell cancers in the salvage after chemotherapy and radiotherapy group (Table 1), because most of the patients treated initially with definitive chemoradiation therapy have these characteristics. In fact, 3 of the 13 patients undergoing salvage esophagectomy also underwent simultaneous laryngectomy because of the proximal esophageal tumor location.

We noted a significant increase in perioperative morbidity and hospital use after salvage esophagectomy (Table 2), which may have been due in part to the locations of the tumors and to the need for more extensive surgery and concomitant procedures such as laryngectomy. ${ }^{13,14}$ Additionally, many of the patients in the salvage after chemotherapy and radiotherapy group were operated on in the beginning of the study period (1980s), when perioperative morbidity rates were higher than for those in the preoperative chemotherapy and radiotherapy group, who underwent surgery predominantly at the end of the study period (1990s). ${ }^{15}$ Other factors that may have contributed to the increased morbidity and hospital use include the increased difficulty of operating many months after the completion of radiation therapy and the higher doses of radiation therapy delivered with definitive chemoradiation therapy, which has been associated with increased morbidity and leak rates in preoperative radiation trials. ${ }^{16-18}$ In fact, a recent randomized intergroup definitive chemoradiation therapy trial was terminated early because of increased toxicity and lower long-term survival in the higher dose chemoradiation therapy arm $(64.8 \mathrm{~Gy}$ vs $50.4 \mathrm{~Gy}) .{ }^{19}$ It is therefore important that oncologists who choose to treat patients with definitive chemoradiation therapy do not use higher doses of radiation, because these higher doses do not improve survival and would presumably also increase the risks of salvage esophagectomy if needed. Our study tried to correlate dose of radiation with morbidity but was not able to see a clear correlation because of the small sample size. In fact, several patients who received more than $60 \mathrm{~Gy}$ of radiation still tolerated salvage esophagectomy without significant morbidity. Additionally, those patients who underwent an Ivor-Lewis esophagectomy with a thoracic anastomosis did not appear to be at increased risk of death from a thoracic leak, because all 5 of these patients survived. The only factor found to be associated with perioperative mortality was the length of time to relapse. Both patients who had relapse more than 50 months after definitive chemoradiation therapy died in the perioperative period, compared with none of those who had relapse 26 months or less after such treatment $(n=11)$. This may have been due to the increased amount of fibrosis seen with time or to late esophageal changes after definitive chemoradia- tion therapy. ${ }^{20}$ The leak rates of cervical anastomoses tend to be higher than those of thoracic anastomoses (10\%-15\% vs $2 \%$ ), which may partly explain our high leak rate in the salvage after chemotherapy and radiotherapy group (38\%) but does not explain all of it. ${ }^{21}$ In an attempt to reduce the leak rates with salvage esophagectomy, we are currently evaluating the benefit of using alternative vascularized conduits, such as colonic or free jejunal interpositions, that have not been within the radiation field and have been associated with low leak rates at our institution and others in high-risk situations. ${ }^{22}$ Although there was not a significant increase in operative mortality, it is important to recognize that this study was performed in a high-volume esophageal referral center (M.D. Anderson Cancer Center) with experience with high-risk esophagectomies. Perioperative morbidity and mortality might have been significantly increased in a low-volume esophageal hospital. ${ }^{10,23}$

Despite the increased morbidity and hospital use noted with salvage esophagectomies, most of the patients survived and were discharged home able to tolerate an oral diet. Furthermore, these patients had few other curative intent therapeutic options, because they had already received maximal amounts of radiation and additional chemotherapy would not have been likely to control the recurrent locoregional disease. Although symptoms could have been palliated with a stent placement, this approach would not have been curative, and other treatments (such as photodynamic therapy and brachytherapy) remain unproven. ${ }^{24-27}$ Most institutions that have adopted a definitive chemoradiation therapy approach to esophageal cancer include patients who have undergone salvage with esophageal resection, and this selective approach may be necessary to achieve long-term survival for some patients. ${ }^{6,9,12}$ In an attempt to identify the subset of patients that benefitted from salvage esophagectomy, we reviewed multiple factors univariately and found that long-term survival was associated with early pathologic stage, complete (R0) resection, and prolonged period to relapse $(>12$ months). Although multivariable analysis could not clearly distinguish the most significant factor because of the small patient numbers and overlap between the factors, early pathologic stage that allowed $\mathrm{R} 0$ resection was associated with an 86-month median survival and with long-term survival for $60 \%$ of patients. In fact, no patient with pathologic T3, T4, or N1 disease survived longer than 7 months. This observation suggests that salvage esophagectomy should be reserved for these patients with early-stage disease, because such treatment of more advanced tumors seldom results in long-term cure. Unfortunately, it is difficult with current endoscopic or CT criteria to define early pathologic stage. A thickened mass or esophagus on posttreatment CT scan or endoscopic ultrasonography does not appear able to distinguish fibrosis from residual or recurrent carcinoma. ${ }^{28,29}$ 
In the future other modalities, such as positron-emission tomography, may be able to help distinguish early-stage patients who could undergo surgical salvage after failed definitive chemoradiation therapy.

In conclusion, this study demonstrated increased morbidity and hospital use after salvage esophagectomy performed after failed definitive chemoradiation therapy relative to planned esophagectomy performed 4 to 6 weeks after preoperative chemoradiation therapy. Despite the increased morbidity, mortality, and hospital use, a subset of patients were cured after salvage esophagectomy, and longterm survival appears to be associated with early pathologic stage (T1 N0, T2 N0), R0 resection, and prolonged time to relapse ( $>12$ months). These data suggest that salvage esophagectomy remains a therapeutic option for carefully selected patients at experienced high-volume esophageal referral centers.

\section{References}

1. Urba SG, Orringer MB, Turrisi A, Iannettoni M, Forastiere A, Strawderman M. Randomized trial of preoperative chemoradiation therapy versus surgery alone in patients with locoregional esophageal carcinoma. J Clin Oncol. 2001;19:305-13.

2. Kelsen DP, Ginsberg R, Pajak TF, Sheahan DG, Gunderson L, Mortimer J, et al. Chemotherapy followed by surgery compared with surgery alone for localized esophageal cancer. $N$ Engl J Med. 1998; 339: 1979-84.

3. Bosset JF, Gignoux M, Triboulet JP, Tiret E, Mantion G, Elias D, et al. Chemoradiotherapy followed by surgery compared with surgery alone in squamous-cell cancer of the esophagus. $N$ Engl J Med. 1997;337:161-7.

4. Walsh TN, Noonan N, Hollywood D, Kelly A, Keeling N, Hennessy TP. A comparison of multimodal therapy and surgery for esophageal adenocarcinoma. N Engl J Med. 1996;335:462-7.

5. Herskovic A, Martz K, al Sarraf M, Leichman L, Brindle J, Vaitkevicius V, et al. Combined chemotherapy and radiotherapy compared with radiotherapy alone in patients with cancer of the esophagus. N Engl J Med. 1992;326:1593-8

6. Cooper JS, Guo MD, Herskovic A, Macdonald JS, Martenson JA, Al Sarraf M, et al. Chemoradiotherapy of locally advanced esophageal cancer: long-term follow-up of a prospective randomized trial (RTOG 85-01). Radiation Therapy Oncology Group. JAMA. 1999;281:1623-7.

7. Araujo CM, Souhami L, Gil RA, Carvalho R, Garcia JA, Froimtchuk $\mathrm{MJ}$, et al. A randomized trial comparing radiation therapy versus concomitant radiation therapy and chemotherapy in carcinoma of the thoracic esophagus. Cancer. 1991;67:2258-61.

8. Wilson KS, Lim JT. Primary chemo-radiotherapy and selective oesophagectomy for oesophageal cancer: goal of cure with organ preservation. Radiother Oncol. 2000;54:129-34.

9. Algan O, Coia LR, Keller SM, Engstrom PF, Weiner LM, Schultheiss TE, et al. Management of adenocarcinoma of the esophagus with chemoradiation therapy alone or chemoradiation therapy followed by esophagectomy: results of sequential nonrandomized phase II studies. Int J Radiat Oncol Biol Phys. 1995;32:753-61.

10. Swisher SG, Deford L, Merriman KW, Walsh GL, Smythe R, Vaporicyan A, et al. Effect of operative volume on morbidity, mortality, and hospital use after esophagectomy for cancer. J Thorac Cardiovasc Surg. 2000;119:1126-34.

11. Smith TJ, Ryan LM, Douglass HO Jr, Haller DG, Dayal Y, Kirkwood $\mathrm{J}$, et al. Combined chemoradiotherapy vs. radiotherapy alone for early stage squamous cell carcinoma of the esophagus: a study of the Eastern Cooperative Oncology Group. Int J Radiat Oncol Biol Phys. 1998;42:269-76.
12. Coia LR, Engstrom PF, Paul A. Nonsurgical management of esophageal cancer: report of a study of combined radiotherapy and chemotherapy. J Clin Oncol. 1987;5:1783-90.

13. Mendenhall WM, Sombeck MD, Parsons JT, Kasper ME, Stringer SP, Vogel SB. Management of cervical esophageal carcinoma. Semin Radiat Oncol. 1994;4:179-91.

14. Pfister DG, Harrison LB, Strong EW, Shah JP, Spiro RW, Kraus DH, et al. Organ-function preservation in advanced oropharynx cancer: results with induction chemotherapy and radiation. J Clin Oncol. 1995; 13:671-80.

15. Swisher SG, Hunt KK, Holmes EC, Zinner MJ, McFadden DW. Changes in the surgical management of esophageal cancer from 1970 to 1993 . Am J Surg. 1995;169:609-14.

16. Sugimachi K, Matsufuji H, Kai H, Masuda H, Ueo H, Inokuchi K, et al. Preoperative irradiation for carcinoma of the esophagus. Surg Gynecol Obstet. 1986;162:174-6.

17. Gignoux M, Roussel A, Paillot B, Gillet M, Schlag P, Favre JP, et al. The value of preoperative radiotherapy in esophageal cancer: results of a study of the E.O.R.T.C. World J Surg. 1987;11:426-32.

18. Akakura I, Nakamura Y, Kakegawa T, Nakayama R, Watanabe H, Yamashita H. Surgery of carcinoma of the esophagus with preoperative radiation. Chest. 1970;57:47-57.

19. Minsky BD, Berkey B, Kelsen DK, et al. Preliminary results of intergroup INT 0123 randomized trial of combined modality therapy (CMT) for esophageal cancer: standard vs. high does radiation therapy. Am Soc Clin Oncol 2000;19:927.

20. Sharma V, Agarwal J, Dinshaw K, Nehru RM, Mohandas M, Deshpande R, et al. Late esophageal toxicity using a combination of external beam radiation, intraluminal brachytherapy and 5-fluorouracil infusion in carcinoma of the esophagus. Dis Esophagus. 2000;13:219-25.

21. Putnam JB, Suell DM, McMurtrey MJ, Ryan MB, Walsh GL, Natarajan $\mathrm{G}$, et al. Comparison of three techniques of esophagectomy within a residency training program. Ann Thorac Surg. 1994;57:319-25.

22. Begg CB, Cramer LD, Hoskins WJ, Brennan MF. Impact of hospital volume on operative mortality for major cancer surgery. JAMA. 1998;280:1747-51.

23. DeMeester TR, Johansson KE, Franze I, Eypasch E, Lu CT, McGill $\mathrm{JE}$, et al. Indications, surgical technique, and long-term functional results of colon interposition or bypass. Ann Surg. 1988;208:460-74.

24. Sanfilippo NJ, Hsi A, DeNittis AS, Ginsberg GG, Kochman ML, Friedberg JS, et al. Toxicity of photodynamic therapy after combined external beam radiotherapy and intraluminal brachytherapy for carcinoma of the upper aerodigestive tract. Lasers Surg Med. 2001;28:27881.

25. Gaspar LE, Winter K, Kocha WI, Coia LR, Herskovic A, Graham M. A phase I/II study of external beam radiation, brachytherapy, and concurrent chemotherapy for patients with localized carcinoma of the esophagus (Radiation Therapy Oncology Group Study 9207): final report. Cancer. 2000;88:988-95.

26. Maier A, Tomaselli F, Gebhard F, Rehak P, Smolle J, Smolle Juttner FM. Palliation of advanced esophageal carcinoma by photodynamic therapy and irradiation. Ann Thorac Surg. 2000;69:1006-9.

27. Greenwald BD. Photodynamic therapy for esophageal cancer. Update. Chest Surg Clin N Am. 2000;10:625-37.

28. Zuccaro G, Rice TW, Goldblum J, Medendorp SV, Becker M, Pimentel R, et al. Endoscopic ultrasound cannot determine suitability for esophagectomy after aggressive chemoradiotherapy for esophageal cancer. Am J Gastroenterol. 1999;94:906-12.

29. Beseth BD, Bedford R, Isacoff WH, Holmes EC, Cameron RB. Endoscopic ultrasound does not accurately assess pathologic stage of esophageal cancer after neoadjuvant chemoradiotherapy. Am Surg. 2000;66:827-31.

\section{Discussion}

Dr Douglas J. Mathisen (Boston, Mass). Congratulations to you and your colleagues for bringing this subject to our attention. This is a topic that we are likely to see more of in years to come, so it is a worthwhile item to bring up at this meeting. I also com- 
mend you colleagues for having the courage to tackle these cases. I think that those of us who have operated on patients who have had failure of previous definitive chemoradiotherapy recognize how difficult these cases are. These patients are difficult to operate on, they are difficult to take care of after the operation, and, as we have seen here, they present some challenges because of the complications that can develop.

First, I think that we would probably both agree that it is difficult to come up with absolute conclusions on the basis of this small experience, which translates into about a case per year. On the other hand, I do think that you have brought to our attention a number of important observations that we need to address. I think that one of the most concerning aspects is the leak rate, and I wonder whether you could share with us the technique that you have used to do the anastomosis. I know that when faced with some of these patients myself who have had either high-dose chemoradiotherapy remotely or are receiving steroids, in addition to the technique that we have used, which I think is a sound one, I have incorporated an intercostal muscle to reinforce the suture line, which I certainly don't do routinely but have done for these highrisk patients.

Second, have you analyzed the CT scans of these patients to look for clues that might discriminate patients who are going to be at increased risk, such as patients who have pulmonary fibrosis, mediastinal fibrosis, or a lot of thickening of the tissues that you are likely to use for anastomosis?

Third, and importantly I think, if we are going to operate on this group of patients, what about their quality of life after this operation? I know that our experience in using high-dose chemoradiotherapy with radiotherapy in the magnitude of $60 \mathrm{~Gy}$ before the operation that some of these patients still have trouble swallowing because of the effects of high doses of radiation. Have you analyzed those survivors for their ability to swallow? Do they need repeated dilations?

Finally, as you have looked at this experience are there certain criteria that you have established in your own mind that might allow you to exclude certain patients? In other words, you stated that on restaging of these patients those with a low stage constitute a favorable group. If they have T3 or T4 disease, they constitute an unfavorable group. Do you have any thoughts about length of time from radiation, the dose of radiation that was used, and the location of the tumor?

Dr Swisher: Thank you, Dr Mathisen. The surgical technique that was used most often was a single-layer hand-sewn anastomosis in the neck and a stapled anastomosis in the chest. The high leak rate that we observed has caused us concern and is probably related to the high radiation level that had been delivered to the esophagus and stomach. In some cases the patients had received up to $90 \mathrm{~Gy}$ of radiation therapy. We have been looking at ways to reduce the leak rate by using alternative vascularized conduits that have not been in the radiation field. These alternative grafts can include colon conduits, which can often be supercharged at the neck, or long-segment interjejunal interpositions, which can be microanastomosed at the neck. Both these conduits bring vascularized grafts that have not been radiated to the operative field. It is important to recognize, however, that only 1 of the 5 patients who had a leak ultimately died of this complication. The most serious problems that we found in our patients were pulmonary prob- lems, and I am uncertain whether these problems were due to the high doses of radiation. Our radiation therapists are careful when they deliver the radiation to ensure that the radiation fields spare the lung. Unfortunately, most of these patients were initially treated at outside hospitals, and the radiation fields may not have been as carefully designed to avoid the lung. We have not been able to pick out factors associated with a high risk of complications, but this may be due in part to the small sample size.

In terms of quality of life, the swallowing function was excellent for the patients who survived long term. The 4 patients who were alive and free of disease longer than 3 years did well and swallowed without difficulty. However, the patients who did not survive long term also did poorly. Their tumors recurred quickly, and their quality of life was poor. I think that this gets to your next point about whether we can select those patients that will do well. Unfortunately, at present we do not have good criteria for selection. As noted in our presentation, those patients who had T3 or greater pathologic class disease seldom survived more than 6 months. Current clinical staging techniques, such as endoscopic ultrasonography or CT scan, are inadequate to pick out the patients with early-stage disease, because many times one can see a mass but is not able to determine whether this represents fibrosis or viable tumor. At the time of the operation many of the patients found on preoperative scans to have a large mass were found to have only a small amount of viable tumor pathologically. So at present we are limited in picking out early-stage disease before the operation. In the future, perhaps positron-emission tomographic activity will help assess the amounts of viable tumor in the primary and distant tumor sites.

Dr Raphael Bueno (Boston, Mass). I would like to congratulate you for presenting these data, because we see these patients more frequently these days as patients seek further therapy. These patients usually have recurrence after complete chemoradiation therapy and tell us that their oncologists told them that they would be cured, and here they are 15 months later with esophageal obstruction. We find it difficult to tell during the operation whether we are dealing with metastatic disease or just postradiation damage. Have you used any particular techniques during the operation, such as more frozen sections, to determine whether you are dealing with fibrosis or penetrating T4 cancers?

Dr Swisher: At the time of operation we perform frozen sections of lymph nodes or suspected metastatic disease. If the lymph nodes show viable tumor and are outside the resected field, then we do not proceed with the operation. To date we have performed resection on patients in whom the lymph nodes could be encompassed in the resection. In light of the current data, however, which indicate no long-term survivors with involved lymph nodes, it might be reasonable to be more selective when deciding whether to proceed, especially if the condition could be palliated by other means, such as stents.

Dr Thomas J. Kirby (Cleveland, Ohio). Could you comment on your indications for surgery, in that you did not have any longterm survivors with a tumor of $\mathrm{T} 2$ or greater? For example, if you did preoperative endoscopic ultrasonography and found that the patient had a T4 lesion, would you still consider that person a candidate for salvage esophagectomy?

Getting back to one of your other points, you said that your high anastomotic leak rate may have been related to preoperative 
radiotherapy of the conduit. Half your lesions were in the upper half of the esophagus, so I would doubt whether your conduit, which I assume was the stomach, was included in the radiotherapy field. Therefore one would have to conclude that the anastomotic leak rate cannot be correlated to radiotherapy of the conduit.

Dr Swisher: It is important to realize that one can be fooled by endoscopic ultrasonography, because a mass on endoscopic ultrasonography does not always represent viable tumor. We have had patients with a large mass that was pathologically only T1 or T2. Additionally, this experience was gained over a long period, so it is only recently that we have had a chance to review it and see how strikingly the long-term survival is related to the pathologic specimen. This question gets to the problem again that it is very difficult at present to clinically stage these relapsed tumors. Perhaps in the future positron-emission tomography or other noninvasive staging modalities will improve the staging.

In terms of the fields of radiation that were delivered, they were delivered at outside hospitals, so it was not possible to evaluate them and correlate them with the leaks. A number of patients had distal esophageal tumors, and we have not looked at whether the leaks occurred primarily among those patients.

Dr Kirby. I would agree with your comments on endoscopic ultrasonography, but it would still provide the surgeon with additional information regarding operability. I have just one follow-up question. If you do not trust the results of endoscopic ultrasonography, do you think that there is a role for thoracoscopy? If you took a biopsy from a lymph node thoracoscopically and found it to represent $\mathrm{N} 1$ or $\mathrm{N} 2$ disease, would you still consider that patient a candidate for an esophagectomy, because you did not have any long-term survivors in that group of patients?

Dr Swisher. That is a good point, and thoracoscopy may be valuable in that situation. Again, we have to be cautious because the risks of thoracoscopy and laparoscopy may also be higher for these patients. It is important to realize that this is a small study with only 13 cases acquired over a long period. We really need to have a prospective study in which we can carefully evaluate these patients in a controlled fashion to pick out which factors are important.

\title{
JTCVS On-Line Manuscript Submission and Review
}

\author{
Please visit http://www.editorialmanager.com/jtcvs/
}

Effective September 15, 2001, authors and reviewers may submit manuscripts and reviews electronically via Editorial Manager, our new Web-based system with full electronic submission, review, and status update capabilities.

As we move from paper to electronic submissions, the Editorial Office will make proxy submissions of all manuscripts accompanied by a diskette containing the electronic files of the text, tables, and figures. Editors, authors, and reviewers will receive automatic e-mails when significant events occur.

We strongly encourage all authors and reviewers to use Editorial Manager. Although we will continue to accommodate the submission of paper manuscripts for some months, our goal is to be completely electronic within 9 to 12 months.

All individuals currently in our database for whom we have e-mail addresses will receive via e-mail a system-assigned username and password that can be used to log in to the system without prior registration. All those not receiving the e-mail must register the first time they use the system.

As with any broad systemic change, the conversion to the new system will take some time to complete. We ask your patience as we replace our in-office database with the new system. We also encourage you to take advantage of the speed and efficiency that the new system will provide for us all: editor, author, reviewer, and publisher. 